\title{
AS LUTAS PELO PASSADO E A CONSTRUÇÃO DE UM FUTURO DEMOCRÁTICO NA AMÉRICA LATINA
}

\author{
Ana Marília Menezes Carneiro ${ }^{1}$
}

JELÍN, Elizabeth. La lucha por el pasado: cómo construimos la memoria social. Buenos Aires: Siglo Veintiuno, 2018.

"Um passado que não passa" ${ }^{2}$. Há pouco mais de duas décadas, o historiador Henry Rousso se valeu desta célebre sentença para referir-se à presença viva e contundente da memória da ocupação alemã e da II Guerra Mundial na sociedade francesa. A potência da expressão utilizada por Rousso, na qual a concepção de que o passado está sempre presente é central, traz à tona um amplo debate envolvendo as relações entre história, memória e o papel do historiador no espaço público. Essas questões ocuparam um lugar de destaque em grande parte da produção historiográfica recente e uma importante contribuição à esse debate é o recém-publicado La lucha por el pasado: cómo construimos la memoria social, de Elizabeth Jelín.

Um dos eixos centrais que perpassa a perspectiva de análise da autora ao longo da obra é afirmação - apenas aparentemente despretensiosa -, de que falar de memórias significa falar de um presente. A memória não é passado, e sim a maneira pela qual os sujeitos constroem um sentido de passado, que sempre se atualiza no presente, temporalidade que contém e constrói a experiência passada e as expectativas futuras. Em tom autobiográfico, com uma escrita híbrida e ao mesmo tempo harmoniosa, "entre o acadêmico, o compromisso cívico-político e a própria subjetividade"3, a autora transita com competência e rigor metodológico na análise do cenário complexo, ambíguo e conflituoso das lutas pela memória do passado recente.

Os estudos desenvolvidos por Elizabeth Jelín - que é socióloga de formação - são um exemplo resultante do processo de renovação historiográfica em curso nos últimos anos na Argentina que envolve o desenvolvimento de um conjunto de pesquisas de caráter histórico também no campo das ciências sociais, marcado por pesquisas e publicações que envolveram dimensões fundamentais vinculadas à experiencias autoritárias, como a cidadania, os direitos humanos, as memórias da repressão política no Cone Sul, as transformações no âmbito da familia e os movimentos sociais. Com uma vasta produção ao longo de uma trajetória acadêmica de mais de três décadas, a autora é uma referência pioneira no campo de estudos sobre memórias e violações a direitos humanos na última ditadura militar argentina ${ }^{4}$. La lucha por el passado é, na realidade, o resultado de reflexões construídas ao longo do seu percurso como pesquisadora, composto a partir da revisão de uma série de textos que foram escritos em momentos diversos da sua carreira. Em última instância, o livro é um produto que nos permite acompanhar o debate sobre a memória inscrito em múltiplas temporalidades, construído em resposta a estímulos e demandas específicas de momentos políticos específicos no contexto argentino.

La lucha por el pasado é uma obra construída a partir de diversas ideias-força, sendo que três delas possuem uma relevância manifesta: em um primeiro eixo de análise, as memórias - sempre no plural apresentam uma historicidade e se desenvolvem em múltiplas temporalidades. Nesse sentido, as memórias surgem através de lembranças, esquecimentos e silêncios em momentos históricos

\footnotetext{
${ }^{1}$ Doutoranda em História pelo Programa de Pós Graduação em História da UniversidadeFederal de Minas Gerais (UFMG). Membro do Laboratório de História do Tempo Presente da UFMG. Email: anammc@gmail.com

${ }^{2}$ ROUSSO, Henri; CONAN, Eric. Vichy, un passé qui ne passe pas. Paris: Fayard, 1994.

${ }^{3}$ JELÍN, Elizabeth. La lucha por el pasado: cómo construimos la memoria social. Buenos Aires: Siglo Veintiuno, 2018 , p. 13.

${ }^{4} \mathrm{Na}$ Argentina, sobretudo a partir da década de 1990, foram produzidos estudos de fôlego sobre a questão da memória e a última ditadura militar. Algumas das obras mais relevantes são: CRENZEL, Emilio. La historia política del Nunca Más: la memoria de las desapariciones en la Argentina. Buenos Aires, Siglo XXI Editores, 2008; SARLO, Beatriz. Tiempo pasado: cultura de la memoria y giro subjetivo. Una discusión, Buenos Aires, Siglo XXI, 2005; VEZZETTI, Hugo. Sobre la violencia revolucionaria: memorias y olvidos, Buenos Aires, Siglo XXI, 2009.
} 
específicos, em função de cenários e das lutas sociais de cada conjuntura. Há momentos, portanto, em que percebemos que as disputas pelas memórias atravessam períodos menos efervescentes, enquanto em outros momentos, as lutas pelas memórias se recrudescem e projetam-se em um cenário bélico, adquirindo novo vigor em contextos de polarização política. O segundo eixo é focado na ênfase da dimensão conflitiva das memórias: atores diversos fazem uso do passado, colocando na esfera pública suas interpretações em função de seus compromissos emocionais e políticos. O terceiro eixo - e talvez o mais provocativo, já que intimamente relacionado a uma dimensão ética - está relacionado às considerações em torno de um dever de memória, conformado pelas relações entre memória, justiça e democracia.

Antes de desenvolver o primeiro eixo de análise, vinculado às capas de temporalidades das memórias, é fundamental especificar de que memórias estamos falando: memórias associadas a processos políticos violentos. A preocupação com as memórias associadas a traumas é relativamente recente no campo acadêmico, vinculada sobretudo às discussões e reflexões emergentes a partir do fim da II Guerra Mundial e das atrocidades cometidas durante o holocausto. A concepção de memória empregada por Elizabeth Jelín sustenta-se nessa dimensão do trauma e da ruptura: "o memorável surge quando rotinas aprendidas e esperadas se quebram, quando um novo acontecimento irrompe $e$ desestrutura. Aí o sujeito se vê envolvido de maneira diferente. O proceso vivido cobra uma vigência que impulsiona depois a busca de sentido desse acontecimento" ${ }^{5}$. É justamente a partir dessa noção de ruptura que a autora principia o livro, recuperando outros processos autoritários ocorridos na Europa para focar a sua análise na experiência pós ditatorial argentina.

A segunda guerra mundial $e$ as atrocidades perpetradas pelo regime nazista tem sido, há mais de cinco décadas, uma referência central para o desenvolvimento da reflexão sobre a maneira pela qual distintos atores sociais e políticos elaboraram e deram sentido ao pasado. A Shoah se converteu em um elemento-chave para se interpretar as múltiplas e recorrentes situações de violência política, massacres e genocídios em todo o mundo, deixando de ser um acontecimento para tornar-se uma metáfora das tragédias do século XX e XXI.

Seria possível transferir, no entanto, de maneira direta, este tipo de experiência à história dos países do Cone Sul? Segundo Jelín, é necessário pensar a especificidade latino-americana. Na Alemanha, a sucessão de conflitos políticos e sociais em relação ao passado e sua à memórias fizeram sentir, na maioria das vezes, sem a presença do Estado como um protagonista privilegiado. Já a história das memórias no Cone Sul emergiu em um momento distinto, em plena Guerra Fria, onde forças políticas internas e os movimentos sociais tiveram um papel fundamental na resistência contra as ditaduras e o papel do Estado no pós-ditatorial foi bastante significativo. Certamente, as experiências ditatoriais e os processos de transição de cada país apresentam suas especificidades, no entanto, como adverte Elizabeth Jelín, "antes de ver essas histórias como autônomas e paralelas, é necessário considerá-las como uma trajetória comum, com fortes interdependências" ${ }^{6}$. Um dos traços em comum compartilhados por Chile, Paraguai, Argentina, Brasil e Uruguai é que o passado ditatorial recente não permaneceu engessado no momento da transição política, continuou sendo parte central do cenário durante as décadas posteriores.

Apesar de não empreender um estudo de história comparada, ao chamar a atenção para a presença de elementos comuns nas trajetórias políticas dos países do Cone Sul, Elizabeth Jelín aponta para uma importante e necessária perspectiva de análise relacional ainda pouco explorada no campo acadêmico, atenta para os diálogos e intercâmbios nos processos ditatoriais e democráticos na perspectiva regional. Nesse sentido, percebemos ao longo de La lucha por el pasado que o caso argentino serve para apreendermos muitas das ambivalências, tensões e recuos inscritos não somente na dinâmica das memórias, mas também no campo empírico, na dinâmica social e político das outras experiências autoritárias do Cone Sul. Essa perspectiva adotada por Jelín faz parte de uma mudança recente no campo de estudos voltados para possibilidade de equiparação do caso argentino com outras experiências traumáticas verificadas no século XX, como o holocausto ou as ditaduras militares latino-americanas. Em muitos dos trabalhos, a ênfase estava posta em estabelecer um contraponto ou uma analogia entre as configurações da memória (individual, coletiva) presentes nessas diversas

\footnotetext{
${ }^{5}$ JELÍN, Elizabeth. La lucha por el pasado: cómo construimos la memoria social. Buenos Aires: Siglo Veintiuno, 2018 , p. 14.

${ }^{6}$ JELÍN, La lucha por el pasado..., p. 41. 
experiências traumáticas, e não na comparação entre essas configurações históricas ${ }^{7}$. Esse panorama tem se modificado nos últimos tempos, com estudos sobre a repressão autoritária que se preocupam em explorar as especificidades da ditadura argentina em comparação com as experiências européias, aprofundando a vertente de análise do processo de construção de memórias concebida a partir das dinâmicas políticas e sociais, como propõe o trabalho de Elizabeth Jelín ${ }^{8}$.

Para dar-se conta da característica dinâmica e fluída das memórias, é importante perceber que os processos de elaboração do passado nos países do Cone Sul assumiram tons diversos em distintas temporalidades, passando pelo protagonismo dos relatos pessoais dos sobreviventes, das representações culturais, da práticas institucionais estatais (julgamentos, comemorações, monumentos, rituais, reparação econômica, políticas de arquivos, lugares de memória). No caso da Argentina, os sentidos do passado produzidos nos anos imediatamente posteriores à transição condenaram a violência do chamado terrorismo de Estado e a violação dos direitos humanos. A incorporação da dimensão dos direitos humanos, sobretudo após a divulgação dos resultados do relatório Nunca Más, pode ser concebida em uma revolução paradigmática: implicou em considerar o ser humano como portador de direitos fundamentais que devem ser garantidos pelo Estado. A partir daí, as políticas de memória na Argentina se desenvolveram a partir da chave da violação aos direitos humanos.

Uma das temporalidades das memórias pode ser apreendida a partir da influência do pensamento feminista contemporâneo, que incorporou a abordagem dos dilemas constitutivos a partir das relações de gênero. Somente no alvorecer do século XXI as demandas dos movimentos feministas foram incorporadas à agenda social $e$ política das transições, alcançando-se o reconhecimento social $e$ político de determinadas violações específicas dos direitos humanos a partir da violência de gênero. Esse tema é abordado em um capítulo específico - e fundamental - de La lucha por el pasado, dedicado a explorar as mudanças na interpretação da violencia sexual como prática repressiva nas últimas décadas.

Certamente, os elementos da teoria de gênero e dos estudos feministas contribuem muito na reflexão sobre o tema da repressão em contextos ditatoriais. Afinal, qual o sentido político de existir uma sala de parto destinada a detentas grávidas na Escuela de Mecânica de La Armada (ESMA)? A indução ao aborto durante práticas de tortura, os abusos sexuais cometidos nos cárceres, o sequestro de recém nascidos. Durante um largo período, muitas destas práticas estiveram invisibilizadas $e$ subsumidas à figura legal de meros "delitos contra à honestidade" antes de serem considerados crimes com uma especificidade própria, de lesa humanidade. A temporalidade em que a perspectiva de gênero se impõe como elemento central e não apenas transversal nos estudos sobre repressão $e$ memórias é recente: refletir sobre o momento em que vieram à tona é pensar que a violência de gênero é estrutural, e que as formas de repressão contra mulheres se legitima e se reproduz nos mais diversos espaços, se prolonga no tempo ${ }^{9}$. Significa, ao fim, o exercício fundamental de se reinterpretar as novas formas de violência institucional e a necessária reflexão crítica que deve estar presente nas questões teóricos-metodológicas que orientam todo trabalho acadêmico e intelectual. Essa é uma das lutas pelo passado a ser travada cotidianamente, como sustenta Jelín.

Passemos ao segundo eixo escolhido para análise do livro, que está intrinsecamente relacionado ao seu título, que aparece flexionado no singular: La lucha por el pasado. As memórias são sempre plurais, como já colocado. Mas cabe questionarmos, seria apenas uma única luta ou diversas lutas em

\footnotetext{
${ }^{7}$ Gabriela Águila assinala essa mudança no campo de estudos sobre a memória em ÁGUILA, Gabriela. La dictadura militar argentina: interpretaciones, problemas, debates. Páginas. Revista digital de la escuela de historia - UNR/ano $1-\mathrm{n}^{\circ} 1$. Rosario, 2008.

${ }^{8}$ Essa perspectiva também é adotada em outros trabalhos recentes, a exemplo de: LVOVICH, Daniel. Historia reciente de pasados traumáticos. De los fascismos y colaboracionismos europeos a la historia de la última dictadura argentina. In: FRANCO, Marina; LEVÍN, Florencia (orgs.). Historia reciente: Perspectivas y desafíos para un campo en construcción. Buenos Aires: Paidós, 2007, p. 97-124 e FEIERSTEIN, Daniel. El genocidio como práctica social. Entre el nazismo y la experiencia argentina. BuenosAires: Fondo de Cultura Económica, 2007.

${ }^{9} \mathrm{Na}$ Argentina, a partir de meados da década de 1990 há um número considerável de literaturas de memória e trabalhos jornalísticos que incorporaram reflexões referentes a violência política e de gênero, a exemplo de Mujeres Guerrilleras. La militancia de los setenta en el testimonio de sus protagonistas femeninas (1997), de Marta Diana e Ese Infierno. Conversaciones de cinco mujeres sobrevivientes de la ESMA (2001) de Munú Actis, Cristina Aldini, Liliana Gardella, Miriam Lewin y Elisa Tokar. No campo acadêmico, há um manifesto crescimento de artigos sobre o tema publicados em revistas científicas e capítulos de livros que integram diversas coletâneas. Vale mencionar ANDÚJAR, Andrea et al. De minifaldas, militancia y revoluciones. Exploraciones sobre los 70 en la Argentina, Buenos Aires: Luxemburg, 2009.
} 
disputa pelo uso do passado?

Os atores sociais e políticos geralmente possuem a intenção de estabelecer uma única narrativa sobre o passado no espaço público, e lutam para impor sua versão como a dominante, a oficial, hegemônica. No entanto, essas tentativas serão sempre questionadas por outros grupos ou indivíduos, uma vez que os processos de construção de memórias estão sempre abertos. Essa perspectiva da dimensão conflitiva das memórias apresenta uma relação íntima com a sua própria concepção de memória, que é sempre produzida a partir do presente.

Maurice Halbwachs foi o primeiro estudioso a cunhar a categoria "memória coletiva". Ao longo das teses apresentadas nas suas obras, a memória possui sempre um caráter social, é eminentemente coletiva, prevalece sobre as representações particulares ${ }^{10}$. Neste sentido, para Halbwachs, apesar de diferenciar a memória coletiva da memória individual, a própria memória individual subsume-se na dimensão coletiva, uma vez que o processo de construção de memórias é necessariamente ancorado em um contexto social, relacionada com um conjunto de suportes ou "quadros" sociais: a família, escola, trabalho, lugares, datas comemorativas, grupos sociais, instituições religiosas, políticas, a vida moral e material. Mas as lembranças, o conteúdo da memória, não podem emergir por eles mesmos a não ser através das questões evocadas no presente.

Essa é, fundamentalmente, uma das principais críticas feitas por Marc Bloch na resenha a obra de Halbawch, publicada em 1925 na Revue de Synthèse. Bloch tece diversos elogios à obra de Halbwachs, mas aponta uma série de críticas relevantes, principalmente no tocante a categoria de memória coletiva. Resumidamente, Bloch entende que a memória coletiva se constrói a partir de um fenômeno de transmissão social, comunicacional, e por isso está sujeita a erros, enganos, mal entendidos, distorções. Neste sentido, a representação do passado através de uma memória coletiva nunca poderia fugir das intervenções de quem o narra, só tem sentido a partir das determinações do presente. E é justamente na percepção desses problemas internos inerentes à memória coletiva que podemos compreender o caráter conflitivo das memórias, porque essa dinâmica está perpassada pela atuação de elementos de dominação e violência simbólica postos em movimento por atores e grupos que intervém no processo de constituição das memórias ${ }^{11}$. Nas palavras de Michael Pollak, é neste momento em que "a memória entra em disputa"12.

É justamente nessa chave da disputa em torno das memórias que se constrói o leimotiv de La Lucha por el pasado. Ao percorrermos os capítulos do livro, percebemos que o argumento central que os entrelaçam são as transformações nas lutas sociais e políticas, nos protagonistas, nos cenários e nas ideias que disputam os mais diversos terrenos, acadêmicos, institucionais, midiáticos. O segundo capítulo é dedicado a analisar a mobilização das lutas políticas e sociais no âmbito acadêmico e intelectual, situando esse movimento em meio ao surgimento de um campo de estudos específicos sobre as memórias. A tese da autora é que a incorporação da perspectiva de gênero, das questões ligadas aos direitos humanos e à memoria social na academia não se deu de maneira independente ou correu em paralelo. Essas questões sempre estiveram em estreita relação e implicaram uma mudança paradigmática que questionou a mirada prevalecente na reflexão social da região latino-americana. Essas perspectivas não se encerraram internamente no campo acadêmico; desenvolveram-se passo a passo com as lutas sociais, com os movimentos pelos direitos humanos, nas políticas pela expansão da cidadania e no campo de criação artística. Em outras palavras: os aportes temáticos, teóricometodológicos no campo do conhecimento científico e intelectual nunca estiveram isolados, fizeram parte do processo histórico de ação no campo político e social.

No terceiro capítulo, Elizabeth Jelín concentra sua análise no movimento de direitos humanos argentino durante a última ditadura militar, no período de transição e nas décadas posteriores. Inicialmente, a questão dos direitos humanos esteve vinculada às demandas por informação sobre o ocorrido durante o regime militar; durante a transição, associada ao âmbito judicial e político; por fim,

\footnotetext{
${ }^{10}$ Em Os quadros sociais da memória (1925), Halbwachs já teria lançados as bases das suas principais teses sobre a memória, mas as desenvolve com maior profundidade em sua obra póstuma A memória coletiva. Cf. HALBWACHS, Maurice. A memória coletiva. São Paulo: Ed. Centauro, 2006 [1950].

11 Pollak chama a atenção para a incapacidade de Halbwachs de enxergar a dimensão da violência simbólica em torno da memória coletiva, compreendendo-a mesmo como um fator de coesão do grupo. Cf. POLLAK, Michael. Memória, esquecimento, silêncio. Estudos Históricos, vol. 2, n. 3. Rio de Janeiro: CPDOC, 1989, p. 3- 15.

${ }^{12}$ POLLAK, Memória, esquecimento, silêncio, p. 4.

386 SÆCUluM - Revista DE História [39]; João Pessoa, jul./dez. 2018.
} 
nas últimas décadas, a questão permanece presente e ainda aberta nas demandas dos organismos de direitos humanos e no campo das políticas públicas, marcada por novos tipos de iniciativas, - desde as práticas de comemoração através de monumentos, parques, museus, recuperação de centros clandestinos de detenção, recuperação e digitalização de arquivos da repressão até a criação de novos grupos (como HIJOS) e novas práticas de contestação, como o escrache.

Os capítulos seguintes trabalham sobre temas específicos: a análise das lutas socio-políticas em torno das políticas de memorialização presentes nas marcas territoriais (sítios de memórias, datas comemorativas do calendário oficial). Além dessa dimensão de materialização das memórias, discutese a história da legitimidade de diversos atores no cenário político argentino, situando a importância central dos distintos contextos de produção de narrativas de testemunho e evidenciando as múltiplas capas em que se expressam essas memórias.

O último eixo de análise da obra de Elizabeth Jelín está focado em um tema incontornável: o dever de memória. O final do século $\mathrm{XX}$ foi marcado por um profícuo movimento de culto à memória, (dos heróis, das vítimas, dos martíres), que se materializou na emergência e na "sacralização" de diversos lugares de memória: museus, arquivos, monumentos, objetos, sítios de memória, rituais comemorativos. Essa obsessão foi amplamente difundida através dos meios de comunicação, um processo que "espetacularizou" o passado e transformou a memória, nas palavras de Enzo Traverso, em um "objeto de consumo, estetizado, neutralizado e rentável" ${ }^{13}$.

Em 1984, no clássico estudo Les lieux de mémoire, a sentença categórica de Pierre Nora já anunciava o diagnóstico de um tempo presente obcecado pela memória:

O dever de memória faz de cada um o historiador de si mesmo. O imperativo da história ultrapassou muito, assim, o círculo dos historiadores profissionais. Não são somente os antigos marginalizados da história oficial que são obcecados pela necessidade de recuperar seu passado enterrado. Todos os corpos constituídos, intelectuais ou não, sábios ou não, apesar das etnias e das minorias sociais, sentem a necessidade de ir em busca de sua própria constituição, de encontrar suas origens ${ }^{14}$.

Sem nos determos aqui nas implicações teóricas e políticas e nas repercussões da interpretação de Pierre Nora sobre as articulações entre história e memória ${ }^{15}$, é relevante destacar que falar de um fenômeno como a obsessão pela memória não é tarefa simples. Não apenas pela complexidade teórico-conceitual, mas sobretudo pela implicação ética e política que está posta depois de todas as atrocidades e a violência cometidas especialmente a partir do século XX.

Em A memória saturada ${ }^{16}$, Régine Robin aponta para um paradoxo na sociedade atual: chegamos a um ponto em que o potencial tecnológico permite a possibilidade material de armazenar, arquivar $e$ conservar todos os dados, informações e discursos produzidos, porém, emergimos em um problema crucial: qual o sentido do acesso a toda essa memória? É contra essa "imensa cacofonia" proveniente da produção desenfreada de memórias, que Robin propõe a realização de uma memória crítica para evitarmos cair em um fetichismo em relação ao passado. Talvez essa percepção de Régine Robin venha ao encontro da perspectiva adotada por Jelín para pensar o sentido dos usos do passado na sociedade argentina.

Embora a preocupação em relação aos "usos" e "abusos" da memória não configure exatamente uma novidade na historiografia ${ }^{17}$, nos últimos anos se consolidou em diversos países da América Latina que passaram por experiências autoritárias um fértil campo de pesquisas interessado em refletir

\footnotetext{
${ }^{13}$ TRAVERSO, Enzo. Historia y Memoria: Notas sobre un debate. In: FRANCO, Marina; LEVIN, Florencia (orgs.). Historia Reciente. Perspectivas y desafíos para un campo en construcción. Buenos Aires: Paidós, 2007, p. 67-97.

${ }^{14}$ NORA, Pierre. Entre memória e história: a problemática dos lugares. Projeto História, São Paulo, n.10, dez. 1993 , p.17.

${ }^{15} \mathrm{O}$ filósofo argentino José Sazbón elabora uma crítica profunda sobre o conceito de memória desenvolvido por Pierre Nora, assinalando a que os textos de Nora são marcados por uma premissa de aniquilação da consciência histórica e a anulação da memória como a apreensão viva de uma permanência. Cf. SÁZBON, José. "Conciencia histórica y memoria". Prismas. Revista de historia intelectual, número 6, 2002.

${ }^{16}$ ROBIN, Régine. A memória saturada. Campinas: Unicamp, 2016.

${ }^{17}$ Embora a relação entre história e memória talvez nunca tenha deixado de ser uma inquietação nos estudos históricos, no final da década de 1980, ocupa um lugar privilegiado na discussão historiográfica francesa. Cf. Tzvtan Todorov em Os abusos da memória (1995) e Paul Ricoeur em A memória, a história, o esquecimento (2000).
} 
sobre a temática do papel ocupado pelas memórias das ditaduras nessas sociedades. Sem dúvidas, a Argentina está na vanguarda desse movimento e La lucha por el pasado conforma um extenso e valioso exemplar nesse campo.

$\mathrm{Na}$ Argentina, a queda da última ditadura militar foi marcada por uma importante consigna: Nunca Más. O imperativo do dever de memória estava manifesto, era necessário lembrar para não repetir. Elizabeth Jelín assinala que no momento das transições pós-ditatoriais no Cone Sul, havia uma relação necessária entre a ativação das memórias do passado e os processos de institucionalização democrática. Essa certeza, para além de um slogan, tornou-se o motor do pacto político selado no âmbito acadêmico e entre os ativistas e políticos progressistas. A pergunta que faz Elizabeth Jelín sobre esse nexo entre memória e democracia é fundamental: "uma política ativa de memória é condição necessária para a construção democrática?"18.

"Lembre-se" é a tônica poderosa inscrita no imperativo de memória, ético e político do Zakhor judaico, onde é imposto um antagonismo irreconciliável entre memória e esquecimento. Yosef Yerushalmi problematiza esse antagonismos através de uma célebre sentença, especialmente cara ao contexto argentino: "seria possível que o antônimo de esquecimento não seja a memória e sim a justiça?". ${ }^{19}$ Do ponto de vista da memória coletiva, ao pensarmos no contexto argentino, poderíamos nos perguntar se não estaríamos diante de uma impressionante vitória, uma vez que foi o primeiro país a instaurar os juicios e foi exitosa em incorporar o ato de lembrar do passado ditatorial como um lema e um dever a ser transmitido para a posteridade - lembremos que, afinal, a sociedade argentina realizava julgamentos a torturadores, enquanto outros países da América Latina declaravam anistias.

No espaço restrito de uma resenha, escolho esboçar uma das mais relevantes proposições de La lucha por el pasado: promover e expandir um dever de memória não significa, necessariamente, a garantia de um futuro mais democrático.

Para ilustrar, pensemos, por exemplo, a partir dos direitos humanos e da sua instalação como paradigma na década de 1980. Na Argentina, a expressão "direitos humanos" está vinculada à violência cometida durante a ditadura, sobretudo a partir de uma perspectiva de direitos civis $e$ políticos. Mas na realidade política contemporânea, a noção de direitos humanos não pode estar restrita apenas às violações ocorridas durante a ditadura militar. É preciso que essa agenda seja ampliada, e incorpore os direitos dos presidiários, o direito ao trabalho, o direito à terra dos povos indígenas, o direito à moradia, às lutas contra os privilégios de cor, sexo e raça, etc. Em outras palavras, as políticas por mais memória nem sempre abrangem as violências estruturais históricas, ancoradas nas desigualdades sociais, econômicas, nos racismos, discriminações, sexismos. A contrapelo do que geralmente se supõe, a memória das violações aos direitos humanos que se produziram no passado ditatorial não significa o rechaço às violações dos direitos de hoje.

Talvez, nesse sentido, ao invés de reivindicarmos mais memória, talvez seja necessário pensarmos a memória - e suas implicações democráticas - em uma chave de duração mais longa, assumindo uma postura não no viés da vitimização, mas de uma luta ativa por mais cidadania ${ }^{20}$. A construção de uma memória crítica, como pretende Régine Robin, talvez envolva uma análise pertinente das relações entre memória, justiça e democracia vinculadas à continuidade de múltiplas desigualdades sociais e a um presente político. Neste sentido, a memória não pode ser concebida como um conteúdo engessado, e sim um processo social dinâmico, que exige um repertório de ação no mundo.

Sabemos que não há uma memória única, e sim várias versões impulsionadas por distintos atores em disputa no espaço público, orientadas por questões de poder simbólico, institucional, material. Em outras palavras, o que está em jogo é uma disputa pela legitimidade do poder. De modo geral, esses atores pretendem impor um único relato e uma única interpretação do passado, que desejam transmitir àqueles que não tiveram a mesma experiência histórica ou que não a compartilham. Qual relato então deveria prevalecer? Ao fim, deveríamos defender a existência de uma única versão de interpretação do

\footnotetext{
${ }^{18}$ JELÍN, La lucha por el pasado..., p. 266

${ }^{19}$ YERUSHALMI, Yosef Hayim. Refleciones sobre el olvido. In: YERUSHALMI, Yosef et al. Usos del Olvido. Argentina: Ediciones Nueva Visión, 1998, p. 26.

${ }^{20}$ Ludmila da Silva Catela, em seu trabalho sobre as comunidades indígenas no norte da Argentina, percebe as violência sofrida por essas comunidades durante a última ditadura militar argentina inscrita em um processo de repressão anterior. Cf. CATELA, Ludmila da Silva. Poder local y violencia. Memorias de la represion en el noroeste argentino. In: ISLA, Alejandro (org.). En los margens de la ley. Inseguridad e violencia en el Cono Sur. Buenos Aires: Paidós, 2007, p. 211-227. 
passado? Defender a postura de uma "memória única", hegemônica, não nos levaria, ao extremo, em impedir a expectativa de construção de uma cidadania ativa, comprometida com a esfera pública $e$ com convicções democráticas? O discurso historiográfico deve ser vinculado a uma memória crítica, a um compromisso intelectual ético-político? Essas não são perguntas que possuem respostas simples $e$ diretas; acompanhando o tom provocativo de La lucha por el pasado, fazem parte de um semnúmeros de questionamentos e uma agenda aberta à reflexão. Afinal, "questionar a relação direta $e$ linear entre memória e democracia implica reconhecer a complexidade da realidade sócio-política $e$ reconhecer que o futuro é sempre aberto e incerto" 21.

Se falar de memórias é sempre falar a partir de um presente, também é falar de um horizonte de futuro. A ideia que guia La lucha por el pasado desloca o referencial interrogante. A pergunta que mobiliza a narrativa historiográfica e o compromisso ético-político do intelectual é colocada desde o futuro: para que - e a quem - serve o passado?

Resenha recebida em 19 jun. 2018.

Aprovada em 10 out. 2018.

${ }^{21}$ JELÍN, La lucha por el pasado..., p. 285. 